\title{
The Influence of SLD Drop Size Distributions on Ice Accretion in the NASA Icing Research Tunnel
}

\author{
Mark G. Potapczuk \\ NASA John H. Glenn Research Center, Cleveland, Ohio, 44135 USA \\ Jen-Ching Tsao \\ Ohio Aerospace Institute, Cleveland, Ohio, 44135 USA
}

\begin{abstract}
An ice shape database has been created to document ice accretions on a 21-inch chord NACA0012 model and a 72-inch chord NACA 23012 airfoil model resulting from an exposure to a Supercooled Large Drop (SLD) icing cloud with a bimodal drop size distribution. The ice shapes created were documented with photographs, laser scanned surface measurements over a section of the model span, and measurement of the ice mass over the same section of each accretion. The icing conditions used in the test matrix were based upon previously used conditions on the same models but with an alternate approach to evaluation of drop distribution effects. Ice shapes resulting from the bimodal distribution as well as from equivalent monomodal drop size distributions were obtained and compared. Results indicate that the ice shapes resulting from the monomodal and bimodal drop size distributions had similar shapes, but the bimodal distributions had greater mass and volume measurements and icing limits that extended further back on the chord of the model.
\end{abstract}

\section{Introduction}

Ice accretion on aircraft surfaces as a result of exposure to supercooled large drops (SLD) is an area of continued research interest to the aerospace community. Methods for simulation of SLD conditions in ground based experimental facilities and within computational tools are currently under development at industrial, academic and governmental institutions around the world. It is clear that most experimental facilities can reproduce aspects of an SLD icing encounter and equally clear that no one facility can reproduce all aspects of an SLD icing cloud. Likewise, computational tools have been developed that can incorporate elements of SLD icing physics however a lack of information concerning the complete range of SLD conditions limits the validation of such tools.

At the NASA Glenn Research Center, work has been underway to extend the capabilities of the Icing Research Tunnel (IRT) to include a broader range of SLD conditions. In addition to a broader range of conditions, the simulation of a bimodal drop size distribution (see [1] for identification of bimodal nature of these distributions) representative of the freezing drizzle (FZDZ), MVD $<40 \mu \mathrm{m}$ distributions contained within FAA regulations for SLD has been developed. This drop-size distribution has been created in the IRT and measured to match the FAA Appendix $\mathrm{O}$ normalized cumulative distribution within $10 \%$ of the total volume for all drop sizes.[2] Furthermore, these bimodal cloud development tests showed experimentally that for two different cases simulated, the measured combined drop-size distributions from two nozzle spray conditions matched the mathematical sum of the two conditions sprayed individually.

In previous test campaigns $[3,4]$, the authors examined the ice Page 1 shapes that are produced with this bimodal distribution and compared such shapes to those formed with similar cloud conditions using standard single nozzle spray conditions, or monomodal distributions. The resulting ice shapes were compared by evaluating cross sections of the shapes and ice shape volumes obtained from laser scan data as well as mass measurements made during the testing. This data provided some insight into the characteristics that differentiate single spray conditions from bimodal spray conditions. This in turn should enable researchers to determine whether bimodal spray cloud recreation is necessary for accurate reproduction of SLD icing conditions.

In this paper, additional testing of the bimodal spray condition was performed to increase the database of ice shape geometries. This was undertaken by adding to the icing conditions tested from the previous study and by use of an alternate approach to selection of icing conditions. The approach taken in this study differed from the earlier studies by eliminating the use of scaling relationships. Instead, the IRT icing conditions were set to be exactly the same for monomodal and bimodal sprays with the only difference being the distributions. This led to similar main ice shape profiles with different mass and volume measurements reflecting the differences in drop sizes contained in the spray cloud.

\section{Facility, Models and Experimental Methods}

\section{Facility}

The Icing Research Tunnel is a closed-loop, atmospheric tunnel, with a $1.83 \mathrm{~m}$ by $2.74 \mathrm{~m}$ by $6.10 \mathrm{~m}(6 \mathrm{ft}$ by $9 \mathrm{ft}$ by $20 \mathrm{ft})$ test section. A tunnel schematic is shown in Fig. 1. The IRT's calibrated test section speed ranges between 50 and 350 knots. The test section temperature can be controlled between $+10{ }^{\circ} \mathrm{C}$ total temperature and $-35^{\circ} \mathrm{C}$ static temperature.

There are two types of spray nozzles in the IRT spray bars: the Standard nozzles that have a higher water flow rate, and the Mod1 nozzles that have a lower water flow rate. Both nozzle types use internal mixing of air and water to create the cloud. The primary difference is in the diameter of the water spray tube at the nozzle exit.

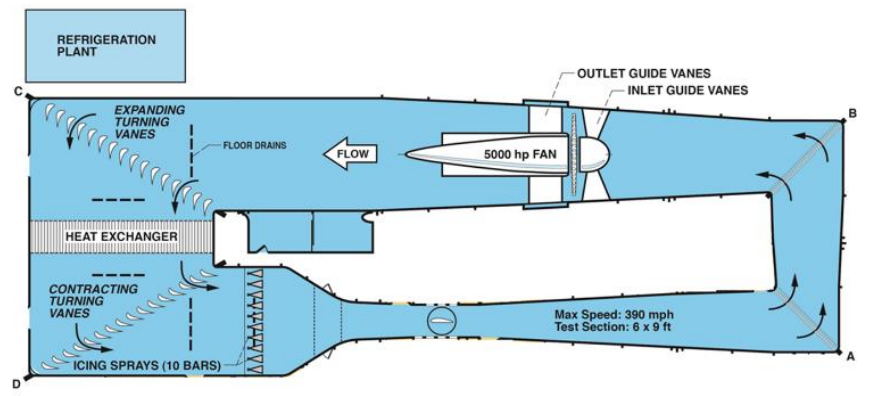

Figure 1. Schematic of the Icing Research Tunnel at NASA Glenn Research Center. 
There are currently 165 Standard nozzles and 88 Mod1 nozzles in the spray bars. Each of the 10 bars in the spraybar system has one air manifold and two water manifolds to run the two nozzle sets. The two nozzle sets may be sprayed individually, or if they are set at the same air pressure, they may be sprayed simultaneously, with different water pressures. Nozzle air pressure (Pair) and delta pressure (expressed as water pressure minus air pressure, or DelP) and nozzle type are varied to create the desired drop size and water content. All water supplied to the IRT spray bars has been filtered and de-ionized.

Drop sizes in the IRT are typically described in terms of median volumetric diameter (MVD), which is the drop diameter at which half the liquid water content volume is contained in smaller drops and half in larger drops. Under "normal" operating conditions, when the spraybar air pressure is 10 psig or higher, the calibrated MVD range of the spray nozzles is between 14 and $50 \mu \mathrm{m}$ for both nozzle sets. When the spraybar air pressure is set below $10 \mathrm{psig}$, larger drops can be created, resulting in a calibrated MVD as high as 270 $\mu \mathrm{m}$ and maximum drop sizes as high as $1200 \mu \mathrm{m}$. This is typically only done with the Mod1 nozzles, since they have a lower flow rate, better matching to the requirements of large-drop certification criteria. For this study however, the Standard nozzles were used as the drop distribution from those nozzles most closely matches the freezing drizzle drop distribution. The calibrated cloud liquid water content (LWC) range of the IRT is between 0.2 and $4.5 \mathrm{~g} / \mathrm{m}^{3}$. A full report on the cloud calibration of the IRT can be found in Ref. 5 .

King-Steen and Ide [2] have developed an approach to reproduce droplet distributions that are quite close to the freezing drizzle, MVD $<40 \mu \mathrm{m}$ condition from Appendix O. Their approach is based upon simultaneous spray from both the Mod1 and Standard nozzles. All the nozzles in the IRT are connected to the same air manifold however the Mod1 and Standard nozzles each have their own water manifold. By selecting a common air pressure and appropriate water pressures, droplet distributions can be created which, when combined, have a distribution which approximates the freezing

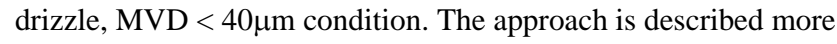
fully in Ref. 2. Figure 2 shows the two individual distributions (Cond1 Mod1 and Cond2 Standard) as well as the combined distribution (Cond3 Mod1 + Std even).

Also shown in Figure 2 is a monomodal distribution produced using the Standard Nozzles. This distribution is the closest single nozzle set distribution in the IRT to the Appendix O, MVD $<40 \mu \mathrm{m}$ distribution which is being modeled for this test program.

Examination of this plot indicates the difference between the two

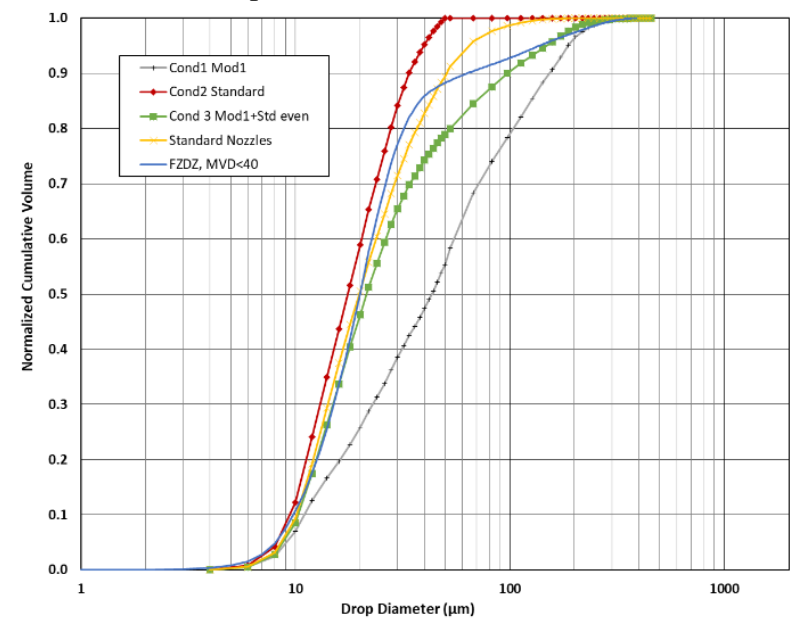

Figure 2. Drop distributions for monomodal and bimodal clouds in the Icing Research Tunnel

Page 2 spray clouds being used in this test. The monomodal distribution has the last $10 \%$ of cumulative volume between 50 and 202.5 microns while the bimodal distribution has the last $10 \%$ of cumulative volume between 97.5 and 382.5 microns.

\section{Description of Models}

The models used in this project were a 21-inch chord, NACA 0012 airfoil model (symmetric profile) and a 72-inch chord, NACA 23012 airfoil model (non-symmetric profile).

The NACA 0012 model is shown mounted in the test section of the IRT in Figure 3. The model is made of aluminum and has a removable leading edge. The model is equipped with 49 pressure taps and two thermocouples were mounted to the surface. The model was mounted vertically in the tunnel on the turntable located at the center of the test section.

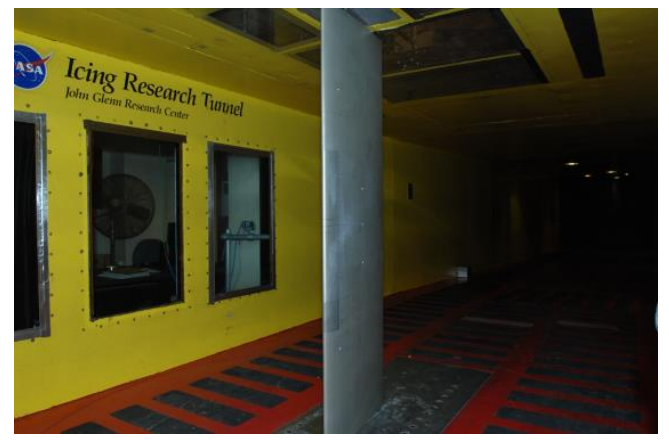

Figure 3. 21-inch chord, NACA 0012 airfoil model mounted verticallv in the test section of the IRT.

The pressure taps were used to determine the zero-degree angle of attack position by checking that the pressure profiles on both surfaces of the airfoil overlapped. The thermocouple was used to evaluate when the model had come into equilibrium with the surrounding airflow. The removable leading edge capability was not used for this project.

The NACA 23012 model is shown mounted in the test section of the IRT in Figure 4. The model is made of aluminum and has a removable leading edge. The model is equipped with 49 pressure taps and two thermocouples were mounted to the surface. The model was mounted vertically in the tunnel on the turntable located at the center of the test section.

The pressure taps were used to determine the zero-degree angle of attack position by checking that the pressure profiles on both surfaces of the airfoil matched published pressure distributions for the NACA 23012 airfoil section. The thermocouple was used

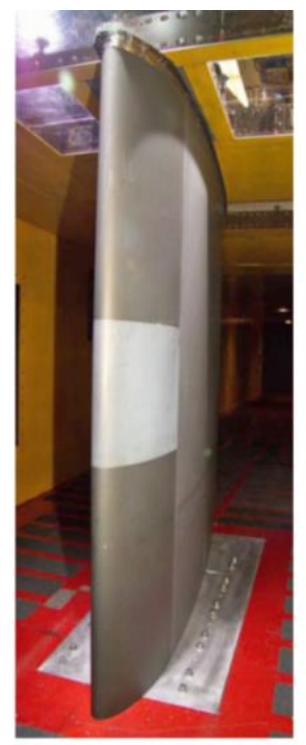

Figure 4. 72-inch chord, NACA 23012 airfoil model mounted vertically in the test section of the IRT. 
to evaluate when the model had come into equilibrium with the surrounding airflow. The removable leading edge capability was not used for this project.

\section{Experimental Approach}

For the previous examinations, the objective was to record and examine the ice shapes that were produced by the bimodal droplet distribution and compare that to the ice shapes produced from a similar droplet distribution that was not bimodal in nature. This was accomplished by utilizing the droplet distribution shown in Figure 2 for one set of conditions and selecting a standard single nozzle distribution, which had a profile close to that of the bimodal distribution. In the previous studies, scaling relationships were used to match accumulation rates and freezing fractions so that the resulting ice shapes should reflect the influence of the cloud drop distributions.

For this study, an alternate approach was used. In this case, it was of interest to match the standard tunnel parameters (i.e. tunnel temperature and velocity, MVD, and LWC) but not attempt to control the cloud drop distributions. This meant that the bimodal distribution was that which had been used in the previous studies while the monomodal distribution was the standard distribution from the spray system for the conditions being tested. This meant that the only difference between the two sets of runs was the drop distribution of the monomodal and bimodal clouds.

Each test run was conducted in the following manner. The tunnel temperature and velocity conditions were set. The spray bar air and water pressures were set. The tunnel was run at the set temperature and velocity conditions and the thermocouples on the model were monitored. When the model temperature matched the tunnel static air temperature, the model was considered to be sufficiently cold to initiate the spray. The spray was initiated and lasted for the prescribed time for the icing condition of that run.

After the spray was stopped and the tunnel velocity was reduced to idle conditions, personnel entered the test section and performed the following tasks. Photographs of the ice on the model were taken from several pre-set locations around the model. A laser scanner system was used to obtain geometric data of the ice shape using the method described by Lee, et al. [6]. The volume measurements performed for this study used the data from the scanner and the software employed for analysis of the scanned data [7] to determine the volume of the outer ice in the same measurement area from which the ice was extracted for the mass measurement. This volume was obtained by calculating the volume of the ice surface and subtracting the volume of the underlying airfoil which was also scanned for the purpose of determining this characteristic of the ice. It isn't clear how accurate the scanner measures the complex three dimensional ice shapes so there are still some uncertainties in that measurement.

Once the ice shapes were scanned, a 12 inch spanwise section of the ice shape was removed from the surface and weighed in order to obtain the accumulated mass. Following the removal of the mass, the model surface was cleaned of all remaining ice and prepared for the next test run.

Examples of the photographs and scans from the testing are shown in Figures 5 through 10. These results are from tests AE2808 and EG2819 which will be described below. The photograph and scan are not at the exact same angle or from the same exact spot along the span and are thus only representative of the data for that run.

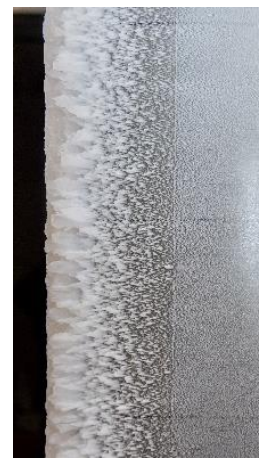

Figure 5. Photograph of leading edge ice accretion on a 21-inch chord NACA0012 airfoil. Test number AE2808.

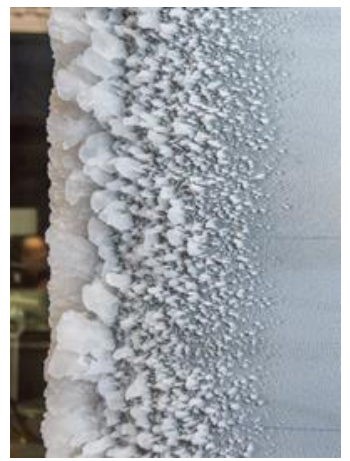

Figure 7. Photograph of leading edge ice accretion on a 72-inch chord NACA23012 airfoil. Suction Surface. Test number EG2819.

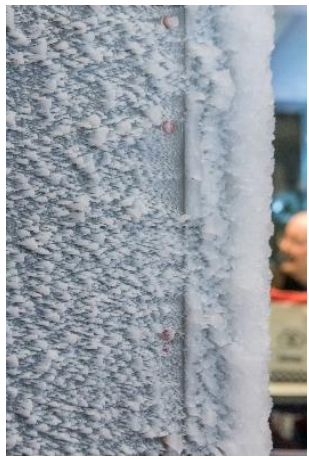

Figure 9. Photograph of leading edge ice accretion on a 72-inch chord NACA23012 airfoil. Pressure Surface. Test number EG2819.

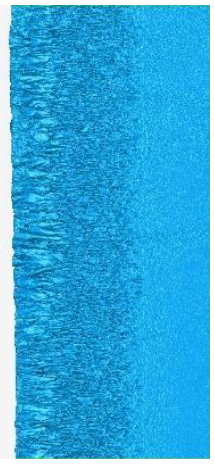

Figure 6. Scan of leading edge ice Test number AE2808.

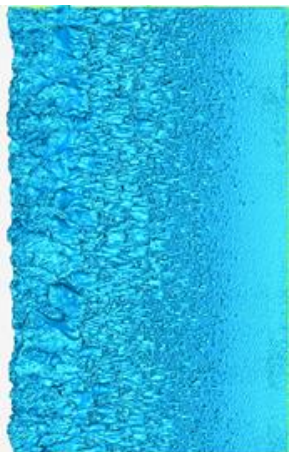

Figure 8. Scan of leading edge ice accretion on a 72-inch chord Surface. Test number EG2819.

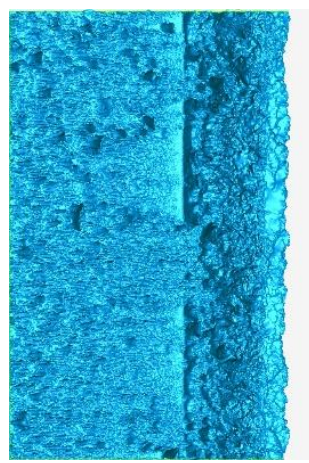

Figure 10. Scan of leading edge ice accretion on a 72-inch chord NACA23012 airfoil. Pressure Surface. Test number EG2819. accretion on a NACA 0012 airfoil. NACA23012 airfoil. Suction

\section{Test Conditions}

The test matrix selected for this study is shown Tables 1 and 2 . The test conditions chosen were based upon what could be produced using the bimodal droplet condition that has been developed for use in the IRT and on previously tested conditions using these models. The monomodal conditions were produced using the Standard nozzles and set at the same velocity, temperature, LWC, MVD, and spray time as their bimodal counterparts. For example, Runs AE2804 and AE2805 were the same icing conditions except with bimodal and monomodal drop distributions, respectively.

In addition to the icing conditions used, the tables also indicate the angle of attack setting for each run, the spray bar settings used to produce the icing clouds, and the freezing fraction at the stagnation point for each run. 


\begin{tabular}{|c|c|c|c|c|c|c|c|c|c|c|c|}
\hline \multicolumn{10}{|c|}{ Test Conditions } \\
\hline $\begin{array}{c}\text { Run } \\
\text { Number }\end{array}$ & $\begin{array}{c}\mathbf{\alpha} \\
(\mathbf{d e g})\end{array}$ & $\begin{array}{c}\mathbf{V} \\
(\mathbf{k t s})\end{array}$ & $\begin{array}{c}\mathbf{M V D} \\
(\boldsymbol{\mu} \mathbf{m})\end{array}$ & $\begin{array}{c}\mathbf{L W C} \\
\left(\mathbf{g} / \mathbf{m}^{3}\right)\end{array}$ & $\begin{array}{c}\mathbf{T}_{\mathbf{t}} \\
\left({ }^{\circ} \mathbf{C}\right)\end{array}$ & $\begin{array}{c}\mathbf{T}_{\mathbf{s}} \\
\left({ }^{\circ} \mathbf{C}\right)\end{array}$ & $\begin{array}{c}\text { Time } \\
(\mathbf{m i n})\end{array}$ & $\mathbf{n}_{\mathbf{0}}$ & $\begin{array}{c}\mathbf{P}_{\text {air }}, \\
(\boldsymbol{p s i g})\end{array}$ & $\begin{array}{c}\text { Mod1 } \\
\mathbf{D P}, \\
(\mathbf{p s i d})\end{array}$ & $\begin{array}{c}\text { STD } \\
\mathbf{D P}, \\
(\mathbf{p s i d})\end{array}$ \\
\hline AE2802 & 4 & 130 & 20.8 & 2.15 & -9.9 & -12.1 & 2.90 & 0.34 & 15 & 80 & 7 \\
\hline AE2803 & 4 & 130 & 20.8 & 2.15 & -9.9 & -12.1 & 2.90 & 0.34 & 25.4 & & 23.3 \\
\hline AE2804 & 0 & 250 & 20.8 & 1.45 & -11.9 & -20.2 & 3.50 & 0.46 & 15 & 80 & 7 \\
\hline AE2805 & 0 & 250 & 20.8 & 1.45 & -11.9 & -20.2 & 3.50 & 0.46 & 25 & & 22.7 \\
\hline AE2806 & 0 & 150 & 20.8 & 1.96 & -14.9 & -17.9 & 4.20 & 0.49 & 15 & 80 & 7 \\
\hline AE2807 & 0 & 150 & 20.8 & 1.96 & -14.9 & -17.9 & 4.20 & 0.49 & 25.4 & & 23.3 \\
\hline AE2808 & 0 & 250 & 20.8 & 1.45 & -11.9 & -20.2 & 3.50 & 0.46 & 25 & & 22.7 \\
\hline AE2809 & 0 & 150 & 20.8 & 1.96 & -14.9 & -17.9 & 4.20 & 0.49 & 25.4 & & 23.3 \\
\hline AE2810 & 4 & 200 & 20.8 & 1.64 & -15.2 & -20.5 & 2.30 & 0.52 & 15 & 80 & 7 \\
\hline AE2811 & 4 & 200 & 20.8 & 1.64 & -15.2 & -20.5 & 2.30 & 0.52 & 25.1 & & 22.9 \\
\hline AE2812 & 0 & 100 & 20.8 & 2.59 & -16 & -17.3 & 5.20 & 0.5 & 15 & 80 & 7 \\
\hline AE2813 & 0 & 100 & 20.8 & 2.59 & -16 & -17.3 & 5.20 & 0.5 & 25.6 & & 23.6 \\
\hline
\end{tabular}

Table 1. Test conditions for 21-inch chord, NACA 0012 airfoil model.

\begin{tabular}{|c|c|c|c|c|c|c|c|c|c|c|c|}
\hline \multicolumn{12}{|c|}{ Test Conditions } \\
\hline $\begin{array}{l}\text { Run } \\
\text { Number }\end{array}$ & $\begin{array}{c}a \\
(\operatorname{deg})\end{array}$ & $\begin{array}{c}\mathrm{V} \\
\text { (kts) }\end{array}$ & $\begin{array}{l}\text { MVD } \\
(\mu \mathrm{m})\end{array}$ & $\begin{array}{l}\text { LWC } \\
\left(\mathrm{g} / \mathrm{m}^{3}\right)\end{array}$ & $\begin{array}{c}\mathrm{T}_{\mathrm{t}} \\
\left({ }^{\circ} \mathrm{C}\right)\end{array}$ & $\begin{array}{c}\mathrm{T}_{\mathrm{s}} \\
\left({ }^{\circ} \mathrm{C}\right)\end{array}$ & $\begin{array}{l}\text { Time } \\
(\min )\end{array}$ & $\mathrm{n}_{0}$ & $\begin{array}{l}\mathbf{P}_{\text {air }} \\
\text { (psig) }\end{array}$ & $\begin{array}{c}\text { Mod11 } \\
\text { DP, } \\
\text { (psid) }\end{array}$ & \begin{tabular}{|c} 
STD \\
DP, \\
(psid)
\end{tabular} \\
\hline EG2814 & 5 & 175 & 20.8 & 1.77 & -4.7 & -8.7 & 5.20 & 0.19 & 15 & 80 & 7 \\
\hline EG2815 & 5 & 175 & 20.8 & 1.77 & -4.7 & -8.7 & 5.20 & 0.19 & 25.1 & & 22.9 \\
\hline EG2816 & 2 & 200 & 20.8 & 1.64 & -7.3 & -12.6 & 0.59 & 0.27 & 15 & 80 & 7 \\
\hline EG2817 & 2 & 200 & 20.8 & 1.64 & $\begin{array}{l}-7.3 \\
\end{array}$ & -12.6 & 0.59 & 0.27 & 25.1 & & 22.9 \\
\hline EG2818 & 5 & 175 & 20.8 & 1.77 & -4.7 & -8.7 & 5.20 & 0.19 & 15 & 80 & 7 \\
\hline EG2819 & 2 & 200 & 20.8 & 1.64 & -7.3 & -12.6 & 6.63 & 0.27 & 15 & 80 & 7 \\
\hline EG2820 & 2 & 200 & 20.8 & 1.64 & -7.3 & -12.6 & 6.63 & 0.27 & 25.1 & & 22.9 \\
\hline EG2821 & 2 & 200 & 20.8 & 1.64 & -26.4 & -31.7 & 4.60 & 0.72 & 15 & 80 & 7 \\
\hline EG2822 & 5 & 175 & 20.8 & 1.77 & -4.7 & -8.7 & 5.20 & 0.19 & 25.1 & & 22.9 \\
\hline EG2823 & 2 & 200 & 20.8 & 1.64 & -26.4 & -31.7 & 4.60 & 0.72 & 25.1 & & 22.9 \\
\hline EG2824 & 2 & 150 & 20.8 & 1.96 & -32.1 & -35.1 & 3.50 & $>.85$ & 15 & 80 & 7 \\
\hline EG2825 & 2 & 150 & 20.8 & 1.96 & -32.1 & -35.1 & 3.50 & 0.85 & 25.4 & & 23.3 \\
\hline EG2826 & 2 & 200 & 20.8 & 1.64 & -7.3 & -12.6 & 6.63 & 0.27 & 15 & 80 & 7 \\
\hline
\end{tabular}

Table 2. Test conditions for 72-inch chord, NACA 23012 airfoil model.

The tables illuminate that there are essentially four geometric configurations for this test campaign, two airfoil shapes each at two angle of attack configurations. This will enable comparisons of monomodal and bimodal ice shapes for these four configurations at several icing conditions. There are also some repeat runs in order to get baseline information on the variability of ice shape, mass and volume for comparison to the differences associated with the cloud conditions.

\section{Results and Analysis}

\section{Comparison of monomodal and bimodal ice shapes for NACA 0012 airfoil model}

As shown in Table 1, there were twelve icing runs using the NACA 0012 airfoil model. Of these runs, ten were monomodal and bimodal pairs with the same icing conditions. Two of the runs were repeat conditions. The results for the monomodal/bimodal pairs are presented in Table 3. The results for the repeatability conditions are presented in Table 4.

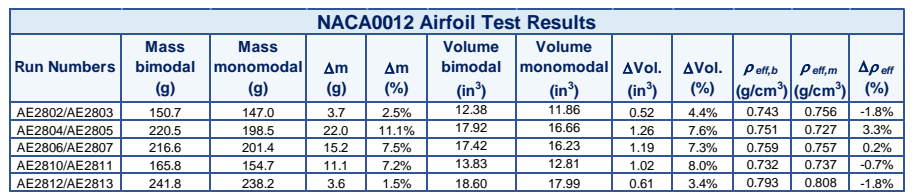

Table 3. Mass and volume results for the 21-inch chord NACA 0012 airfoil. Monomodal and bimodal cloud distributions for the same icing condition.

\begin{tabular}{|c|c|c|c|c|c|c|c|c|c|c|c|}
\hline \multicolumn{12}{|c|}{ NACA0012 Airfoil Repeatability Test Results } \\
\hline Run Numbers & $\begin{array}{c}\text { Mass } 1 \\
\text { (g) }\end{array}$ & $\begin{array}{c}\text { Mass 2 } \\
\text { (g) }\end{array}$ & $\begin{array}{l}\Delta \mathrm{m} \\
(\mathrm{g})\end{array}$ & $\begin{array}{l}\Delta \mathrm{m} \\
(\%)\end{array}$ & $\begin{array}{c}\text { Volume } 1 \\
\left(\text { in }^{3}\right)\end{array}$ & $\begin{array}{c}\text { Volume } 2 \\
\left(\mathrm{in}^{3}\right)\end{array}$ & $\begin{array}{c}\Delta \text { Vol. } \\
\left(\mathrm{in}^{3}\right)\end{array}$ & $\begin{array}{l}\begin{array}{l}\Delta \text { Vol. } \\
(\%)\end{array}\end{array}$ & \begin{tabular}{|c|}
$\rho_{\text {eft, }}$ \\
$\left(\mathrm{g} / \mathrm{cm}^{3}\right)$
\end{tabular} & \begin{tabular}{|c|}
$\begin{array}{c}\rho_{\text {eft }}, \mathrm{m} \\
\left(\mathrm{g} / \mathrm{cm}^{3}\right)\end{array}$ \\
\end{tabular} & $\begin{array}{l}\Delta \rho_{\text {eft }} \\
(\%)\end{array}$ \\
\hline AE280 & $\begin{array}{l}198.5 \\
2014\end{array}$ & $\begin{array}{l}197.5 \\
199.5\end{array}$ & $\begin{array}{l}1.0 \\
119\end{array}$ & $0.5 \%$ & $\begin{array}{l}16.66 \\
16.23\end{array}$ & $\begin{array}{l}16.58 \\
16.27\end{array}$ & 0.08 & $0.5 \%$ & \begin{tabular}{|l|}
0.727 \\
0.757
\end{tabular} & \begin{tabular}{|l|l|}
0.727 \\
0.748
\end{tabular} & $0.0 \%$ \\
\hline
\end{tabular}

Table 4. Mass and volume results for the 21-inch chord NACA 0012 airfoil. Repeat runs to determine ice shape variability.

Page 4
The run number entries in Table 3 list the bimodal and monomodal (standard nozzles) tests in that order. The mass and volume values for each cloud distribution are as labeled in the table. The run number entries in Table 4 list the runs that were repeat conditions. Mass 1 and Volume 1 correspond to the first run number in the pair and Mass 2 and Volume 2 correspond to the second run number in the pair. The ratio of mass to volume is presented as the effective density value listed in these tables.

The ice shape profiles for these runs are shown in Figures 11 through 17. These figures are centerline cuts from the scanned data for each test run. Figures $11-15$ show comparisons of the monomodal/bimodal pairs while figures 16 and 17 show the tracings from the repeat runs. In all the ice shape tracings for monomodal/bimodal pairs, the blue curve is always the bimodal condition and the red curve is always the equivalent monomodal condition.

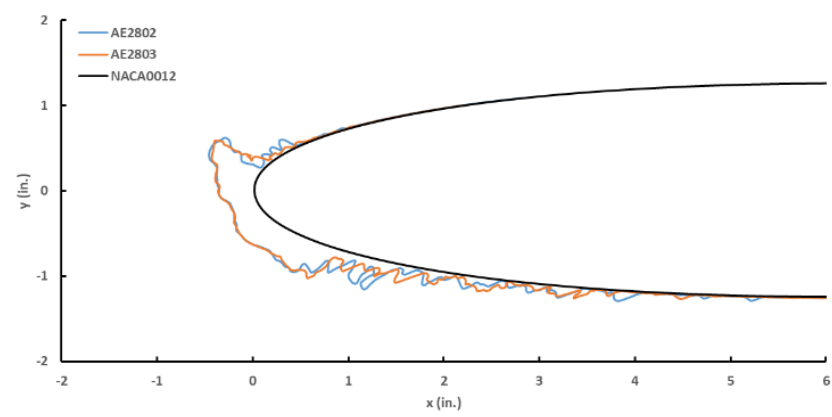

Figure 11. Ice shape profiles for runs AE2802 and AE2803 from center line of 21-inch chord NACA 0012 airfoil model.

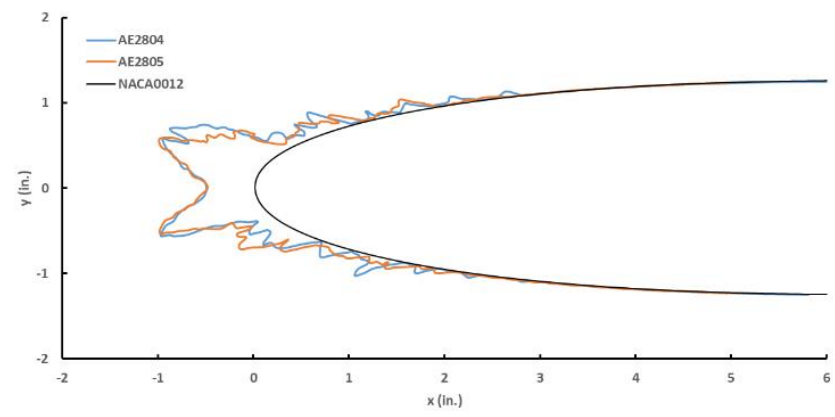

Figure 12. Ice shape profiles for runs AE2804 and AE2805 from center line of 21-inch chord NACA 0012 airfoil model.

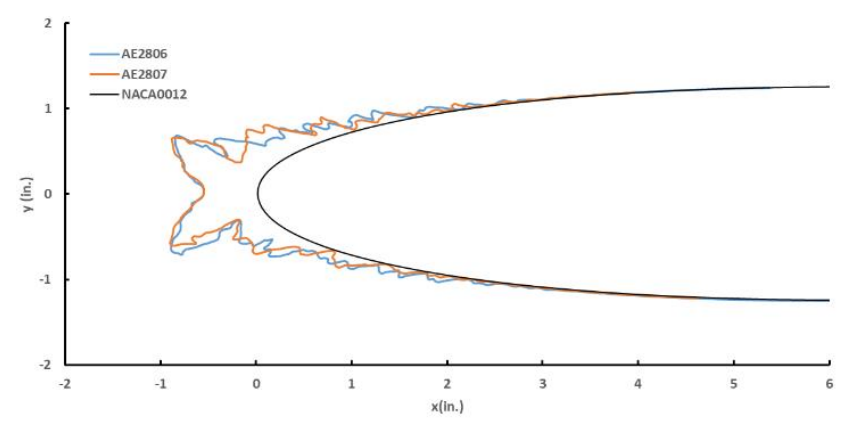

Figure 13. Ice shape profiles for runs AE2806 and AE2807 from center line of 21-inch chord NACA 0012 airfoil model.

The ice shape profile results show that both the monomodal/bimodal pairs as well as the repeat runs are quite similar in shape. However, some differences begin to emerge when the mass and volume values are examined. The difference in measured mass values between the 
monomodal and bimodal runs range from $1.5 \%$ to $11.1 \%$ while for the repeat runs the difference in measured mass was $1 \%$ and less.

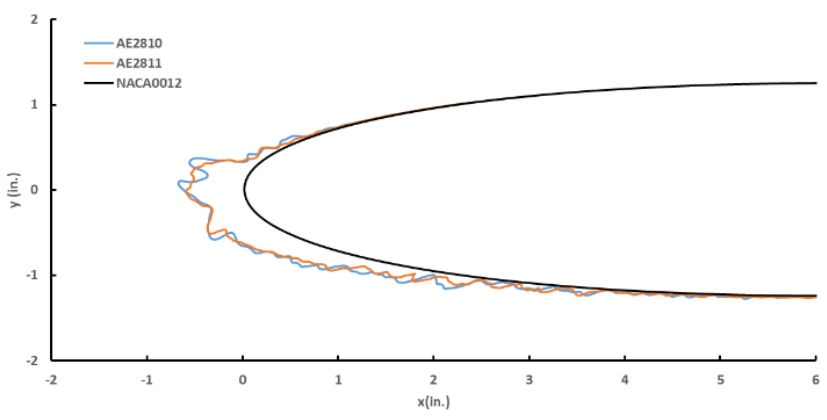

Figure 14. Ice shape profiles for runs AE2810 and AE2811 from center line of 21-inch chord NACA 0012 airfoil model.

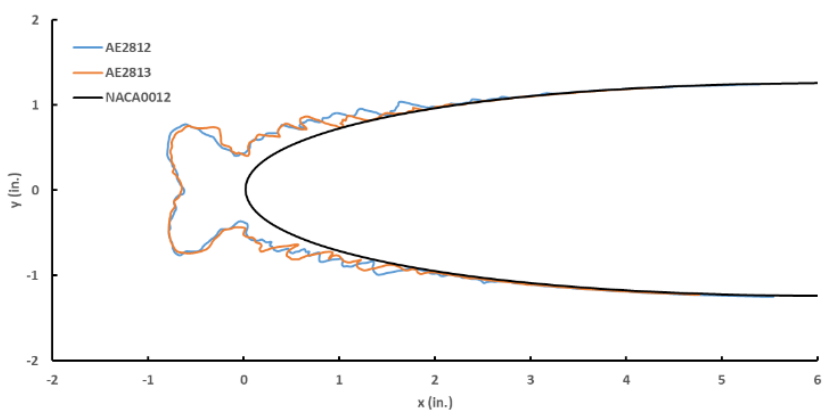

Figure 15. Ice shape profiles for runs AE2812 and AE2813 from center line of 21-inch chord NACA 0012 airfoil model.

Likewise, for the volume measurements the difference between the monomodal and bimodal runs range from $3.4 \%$ to $8 \%$ while for the repeat runs the difference in measure volume was less than $1 \%$. In all comparisons, the bimodal mass and volume values were larger than the corresponding monomodal results.

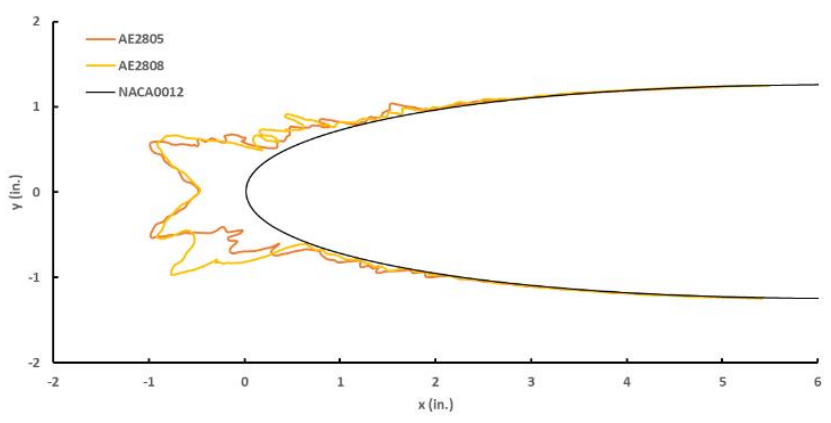

Figure 16. Ice shape profiles for repeat runs AE2805 and AE2808 from center line of 21-inch chord NACA 0012 airfoil model.

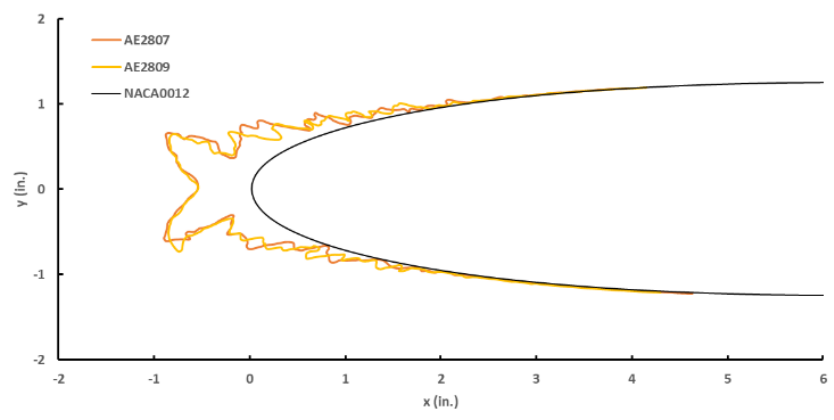

Figure 17. Ice shape profiles for repeat runs AE2807 and AE2809 from center line of 21-inch chord NACA 0012 airfoil model.
Figure 16 illustrates how multiple pieces of information are needed to characterize ice shape comparisons. Of the ice shape profiles for this series of tests it would appear to have the greatest difference between runs, yet for this case both the mass and volume values differ by only $0.5 \%$. The main ice profile difference in this figure is the additional ice horn at $y=-1.0$ inches. This could be a result of one of the localized ice feathers seen in Figure 5 being captured in the tracing from AE2808 and not in AE2805.

In order to better understand the cause of the differences in mass and volume while the ice shapes appear equivalent, the LEWICE [8] ice accretion program was used to examine the effect of drop size on the collection efficiency for the two angle of attack configurations used in this study. Since the main difference in the two cloud profiles for this work, as shown in Figure 2, is that the bimodal distribution has approximately ten percent of its volume in drop sizes between 100 and 200 microns while the monomodal distribution has less than one percent in that same range, the LEWICE code was run with these drop sizes to illustrate the differences in collection efficiency. The code could have been run with drop distributions that match the curves in Figure 2 but it was more illustrative to use single drop sizes at different velocities and model configurations.

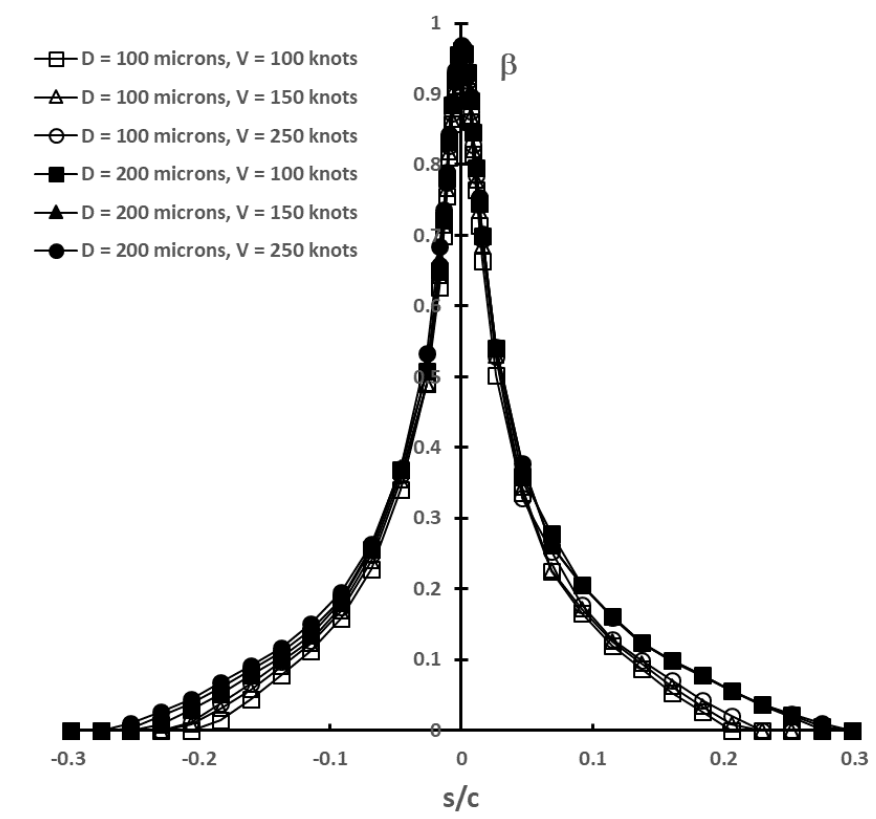

Figure 18. LEWICE collection efficiency results for the 21-inch NACA 0012 airfoil at $0^{\circ}$ angle of attack.

Figure 18 shows that the 200 micron drop sizes resulted in larger collection efficiency values than the case for 100 micron drop sizes. This is most prevalent at the impingement limits where the ice accumulation consists of numerous small feathers. It is difficult to notice the differences in ice shape for these regions from twodimensional cuts, as seen in Figures 11-17. The collection efficiency values near the stagnation region are not that different between the 100 and 200 micron cases and this is reflected in the very similar main ice shapes seen in the figures. This result along with the fact that only about ten percent of the cumulative volume resides in drop sizes between 100 and 200 microns can explain the similar ice shapes but larger mass values for the bimodal cloud conditions. The main shape near the leading edge is the same since most of the cloud is distributed in the same manner for both the monomodal and bimodal sprays. However, the overall larger collection efficiency over the entire impingement region is consistent with the higher mass and volume measurements from the testing. 


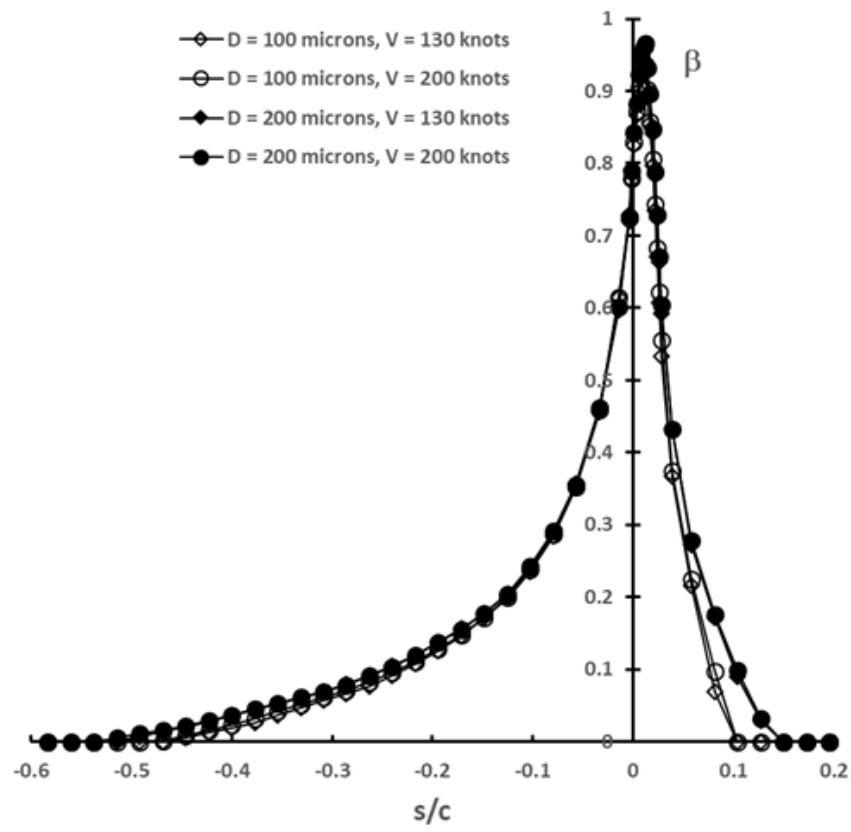

Figure 19. LEWICE collection efficiency results for the 21-inch NACA 0012 airfoil at $4^{\circ}$ angle of attack.

Figure 19 shows similar collection efficiency results for the $4^{\circ}$ angle of attack conditions run with the NACA 0012 airfoil. These results show the same dependence of collection efficiency upon drop size and a much smaller dependence upon air velocity. A bit more noticeable in this plot is the difference in impingement limits. This is as expected and is also the case for the $0^{\circ}$ angle of attack runs but just more noticeable here. The ice shape profiles, mass differences, and volume differences were not significantly different from the $0^{\circ}$ angle of attack runs.

For all of the NACA 0012 runs, the general results indicate that the drop distribution does not substantially alter the ice shape produced while it can impact the mass and volume measurements as well as the impingement limits. This latter result is more of a deduction from the computational simulation. Actual icing limits were not documented during the testing and the scanner results as well as photographs do not provide sufficient information to specify icing limits.

\section{Comparison of monomodal and bimodal ice shapes for NACA 23012 airfoil model}

There were thirteen icing runs using the NACA 23012 airfoil model. Of these runs, twelve were monomodal and bimodal pairs with the same icing conditions. Two of the runs were repeat conditions of bimodal distributions and one was a repeat of a monomodal distribution. As in the case of the NACA 0012 testing, these repeat conditions were run to get a baseline for the variability of mass and volume measurements to enable evaluation of the differences found in the monomodal/bimodal pairs. The results for the monomodal/bimodal pairs are presented in Table 5. The results for the repeatability conditions are presented in Table 6 .

\begin{tabular}{|c|c|c|c|c|c|c|c|c|c|c|c|}
\hline \multicolumn{12}{|c|}{ NACA23012 Airfoil Test Results } \\
\hline Run Numbers & $\begin{array}{c}\text { Mass } \\
\text { bimodal } \\
\text { (g) }\end{array}$ & $\begin{array}{c}\text { Mass } \\
\text { monomodal } \\
(\mathrm{g})\end{array}$ & $\begin{array}{l}\Delta \mathrm{m} \\
(\mathrm{g})\end{array}$ & $\begin{array}{l}\Delta \mathrm{m} \\
(\%)\end{array}$ & $\begin{array}{c}\text { Volume } \\
\text { bimodal } \\
\left(\mathrm{in}^{3}\right)\end{array}$ & $\mid \begin{array}{c}\text { Volume } \\
\text { monomodal } \\
\left(\text { in }^{3}\right)\end{array}$ & $\begin{array}{c}\Delta \text { Vol. } \\
\left(\text { in }^{3}\right)\end{array}$ & $\begin{array}{c}\begin{array}{c}\Delta \text { Vol. } \\
(\%)\end{array}\end{array}$ & $\begin{array}{c}\rho_{\text {ett,b }} \\
\left(\mathrm{g} / \mathrm{cm}^{3}\right)\end{array}$ & $\begin{array}{c}\rho_{\text {ett,m }} \\
\left(\mathrm{g} / \mathrm{cm}^{3}\right)\end{array}$ & \begin{tabular}{|c|}
$\Delta \rho_{\text {etf }}$ \\
$(\%)$
\end{tabular} \\
\hline EG2814/EG2815 & 476.8 & 385.0 & 91.8 & $23.8 \%$ & 34.09 & 30.28 & 3.81 & $12.6 \%$ & 0.854 & 0.776 & \begin{tabular}{|l|}
$10.0 \%$ \\
\end{tabular} \\
\hline EG2816/EG2817 & 58.3 & $\begin{array}{l}3050.0 \\
50.2 \\
\end{array}$ & $\begin{array}{l}9.0 \\
8.1 \\
\end{array}$ & $\begin{array}{l}16.1 \% \\
\end{array}$ & 3.64 & 3.12 & 0.52 & $\begin{array}{l}1.26 \% \\
16.7 \% \\
\end{array}$ & \begin{tabular}{|l|}
0.977 \\
0.977 \\
\end{tabular} & \begin{tabular}{|l|}
0.982 \\
\end{tabular} & \begin{tabular}{|l|}
$-0.5 \%$ \\
\end{tabular} \\
\hline EG2818iEG2822 & 478.5 & 381.0 & 9.1 & $25.6 \%$ & 42.57 & 31.09 & 11.48 & \begin{tabular}{|l|l|}
$36.9 \%$ \\
\end{tabular} & 0.686 & 0.748 & $-8.3 \%$ \\
\hline EG2819IEG2820 & 667.0 & 549.6 & 117.4 & $21.4 \%$ & 52.47 & 43.07 & 9.40 & \begin{tabular}{|l|l|}
$21.8 \%$ \\
\end{tabular} & 0.776 & 0.779 & $-0.4 \%$ \\
\hline EG2821/EG2823 & 467.4 & 361.7 & 105.7 & $29.2 \%$ & 32.65 & 25.29 & 7.36 & $29.1 \%$ & 0.874 & 0.873 & $0.1 \%$ \\
\hline EG2824/EG2825 & 320.6 & 320.0 & 0.6 & $0.2 \%$ & 23.67 & 24.93 & -1.26 & \begin{tabular}{|l|l|}
$-5.1 \%$ \\
\end{tabular} & \begin{tabular}{|l|l|}
0.827 \\
\end{tabular} & \begin{tabular}{l|l|l|l}
0.783 \\
\end{tabular} & \begin{tabular}{|l|}
$5.5 \%$ \\
\end{tabular} \\
\hline
\end{tabular}

Table 5. Mass and volume results for the 72-inch chord NACA 23012 airfoil. Monomodal and bimodal cloud distributions for the same icing condition.

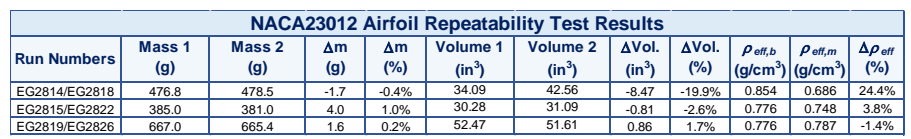

Table 6. Mass and volume results for the 72-inch chord NACA 23012 airfoil. Repeat runs to determine ice shape variability.

The run number entries in Table 5 list the bimodal and monomodal (standard nozzles) tests in that order. The mass and volume values for each cloud distribution are as labeled in the table. The run number entries in Table 6 list the runs that were repeat conditions. Mass 1 and Volume 1 correspond to the first run number in the pair and Mass 2 and Volume 2 correspond to the second run number in the pair. As in the previous section, the ratio of mass to volume is presented as the effective density value listed in these tables.

The ice shape profiles for these runs are shown in Figures 20 - 25 and 27 - 29. These figures are centerline cuts from the scanned data for each test run. Figures $20-25$ show comparisons of the monomodal/bimodal pairs while figures 27 - 29 show the tracings from the repeat runs.

The ice shape comparisons shown above are similar to the results with the NACA 0012 airfoil in that there was little difference in shape between the ice shapes produced with the monomodal drop distribution and those produced with the bimodal distribution. The mass and volume measurements also indicated the same result as for the NACA 0012 airfoil, that is, the bimodal distributions uniformly produced larger mass and volume results than the monomodal counterparts. Additionally, for this set of icing runs we can see from

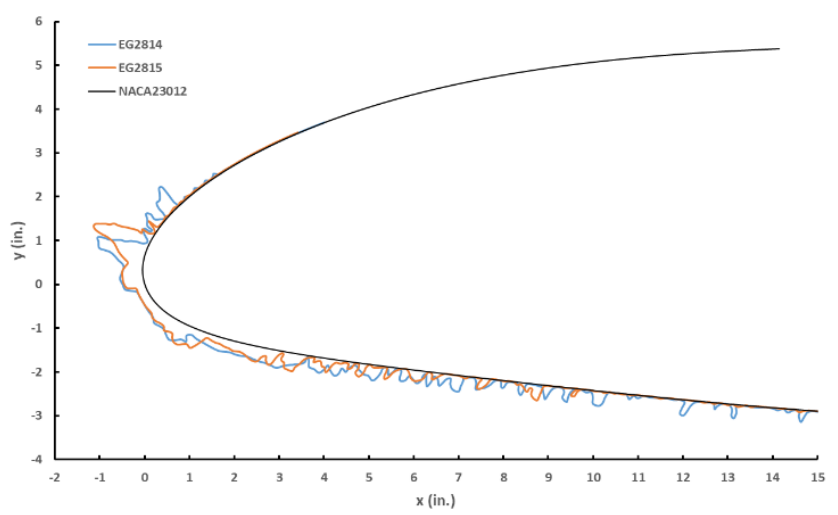

Figure 20. Ice shape profiles for runs EG2814 and EG2815 from center line of 72-inch chord NACA 23012 airfoil model.

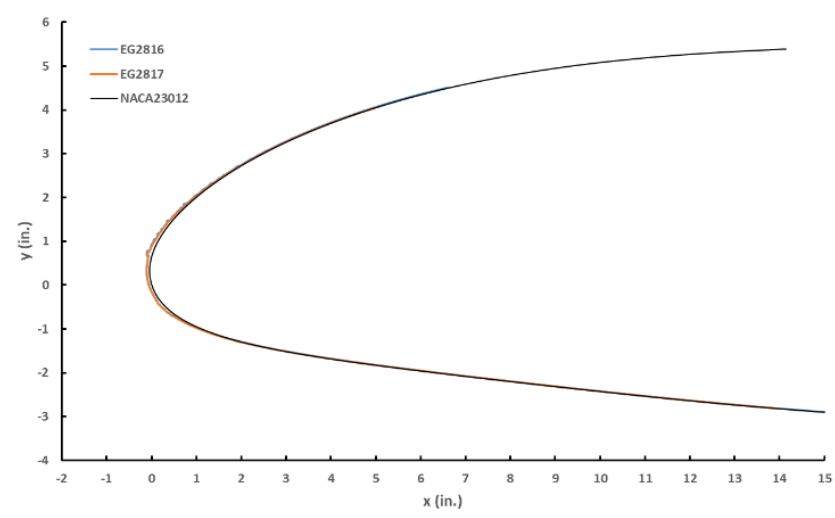

Figure 21. Ice shape profiles for runs EG2816 and EG2817 from center line of 72-inch chord NACA 23012 airfoil model. 
Figures 20 and 22 that even when the ice shape comparisons look better for one case the mass and volume measurements can show a different outcome. In this case, the ice shape comparison in Figure 22 seems to be better than that shown in Figure 20, yet the mass difference between EG2818 and EG2822 (Figure 22) is slightly higher than that between EG2814 and EG2815 (Figure 20). Likewise, the volume difference between EG2818 and EG2822 is almost three times the value of the difference between EG2814 and EG2815. Looking at the volume value for EG2818 seems to indicate the reason here as that value $42.57 \mathrm{in}^{3}$ seems to be substantially more than the other three results despite the mass value being only $0.4 \%$ different than that of its equivalent run, EG2814.

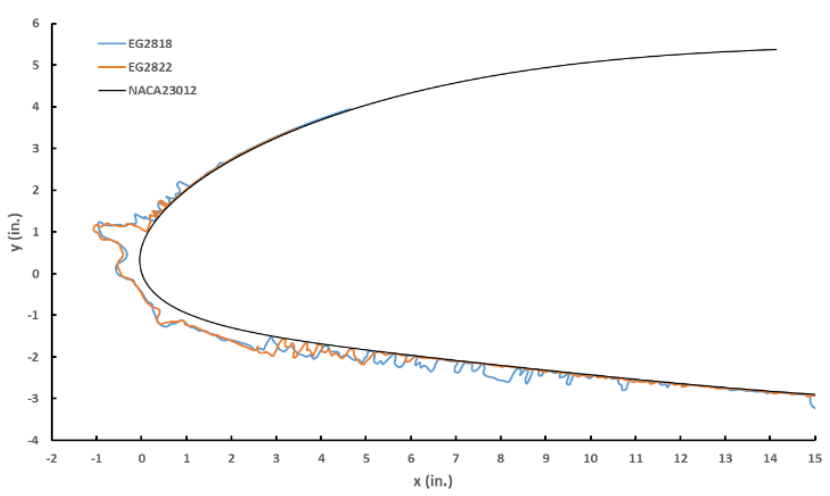

Figure 22. Ice shape profiles for runs EG2818 and EG2822 from center line of 72-inch chord NACA 23012 airfoil model.

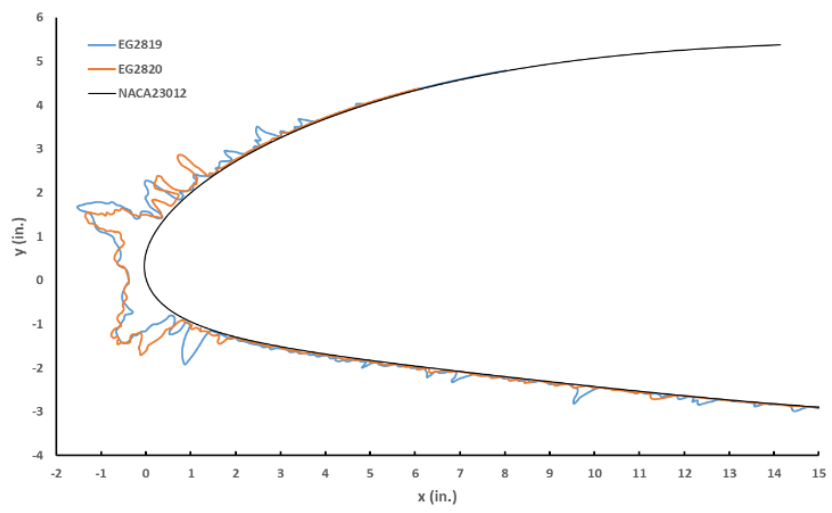

Figure 23. Ice shape profiles for runs EG2819 and EG2820 from center line of 72-inch chord NACA 23012 airfoil model.

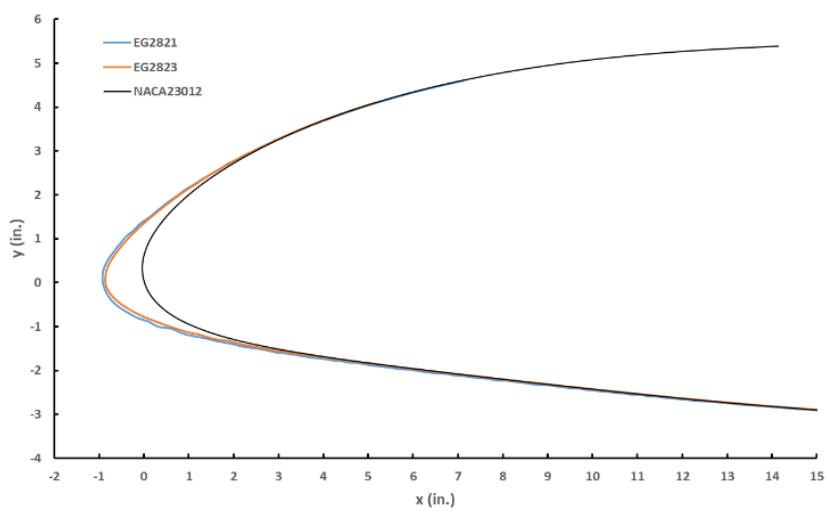

Figure 24. Ice shape profiles for runs EG2821 and EG2823 from center line of 72-inch chord NACA 23012 airfoil model.

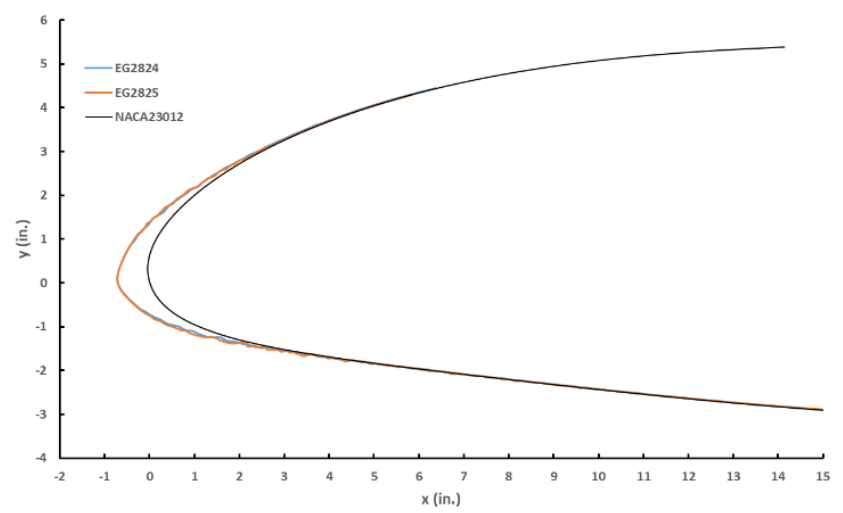

Figure 25. Ice shape profiles for runs EG2824 and EG2825 from center line of 72-inch chord NACA 23012 airfoil model.

Further examination of Figure 22 gives an indication of the differences despite the closely matched main ice shapes. There is quite a bit more ice aft of the main ice shape for the bimodal spray condition, EG2818. A single ice shape tracing at one spanwise location does not tell the whole story. Examining the photographs does however indicate this trend is sustained across the span. Shown below are images from EG2818 and EG2822 that include both the main ice shape and the ice roughness that formed aft of the main shape. As the tracings show the main ice shapes are very similar while the ice shape formed with the bimodal spray, Figure 26a, has more ice aft of the main shape than is seen on the ice shape formed with the monomodal spray, Figure 26b. (Note: These photographs were not taken at the exact same location and angle so there are some differences in scale. However they illustrate the main point of the discussion.)

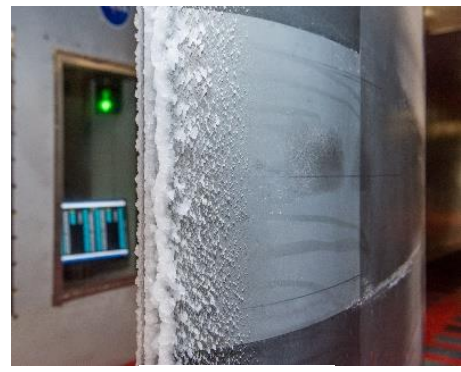

(a) - EG2818

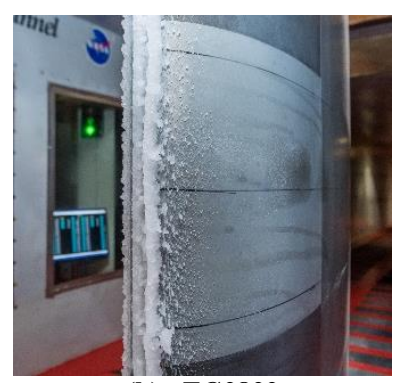

(b) - EG2822
Figure 26. Ice shape photographs for runs EG2818 and EG2822 showing suction surface of 72-inch chord NACA 23012 airfoil model.

The rime ice cases, shown in Figures 24 and 25, show even less difference in ice shape profile than the other cases. There are, however, differences in mass and volume. Again the bimodal runs contain more mass than the monomodal cases. There is a noticeable difference in shape between EG2821 and EG2823 with the bimodal condition producing a shape that is just slightly thicker all around than the monomodal condition. This resulted in the largest mass difference of the rime ice shapes, 105.7 grams or $29.2 \%$ difference in mass. On the other hand, the mass difference between EG2824 and EG2825 was only 0.5 grams or $0.2 \%$ difference in mass. It isn't clear at this point why one pair produced a relatively large difference while the other pair resulted in hardly any difference at all.

The repeat runs show similar results to those of the NACA 0012 runs in that the ice shape tracings indicate the same sort of variation as do the monomodal/bimodal pairs but the mass and volume results show smaller variations than the monomodal/bimodal pairs. 
Comparing Figure 27 with Figures 20 and 22 shows the variation in the amount of ice roughness accumulated on the pressure surface of the NACA 23012 airfoil. While both the bimodal runs, EG2814 and EG2818, have ice roughness well beyond the main ice shape, EG2815 and EG2822 have less ice aft of the main shape. The ice mass differences between the monomodal/bimodal pairs are over $20 \%$ while the repeat runs differ by less than $1 \%$. The volume measurements do not show quite as clear a picture as the mass measurements. The volume difference for this repeat case is $19.9 \%$ which is between the values of $12.6 \%$ for EG2814/EG2815 and $36.9 \%$ for EG2818/EG2822. The volume measurement for EG2818 seems a little out of line with all other repeat volume measurements so some further examination of that case may be needed.

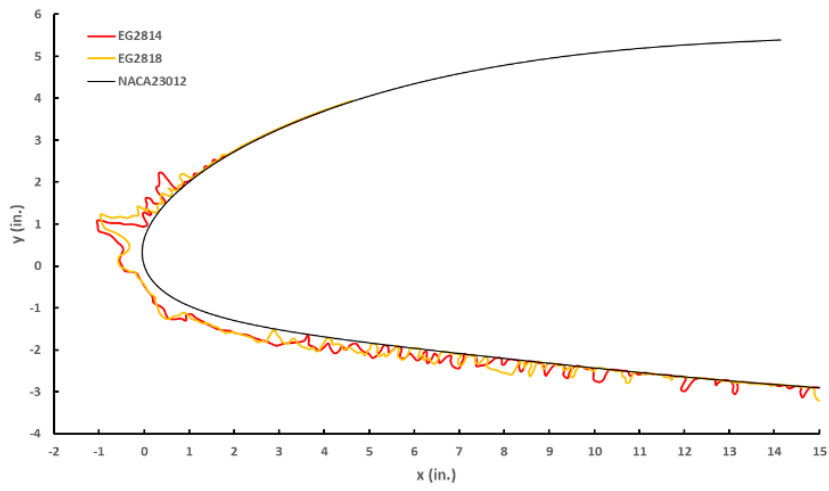

Figure 27. Ice shape profiles for repeat runs EG2814 and EG2818 from center line of 72-inch chord NACA 23012 airfoil model.

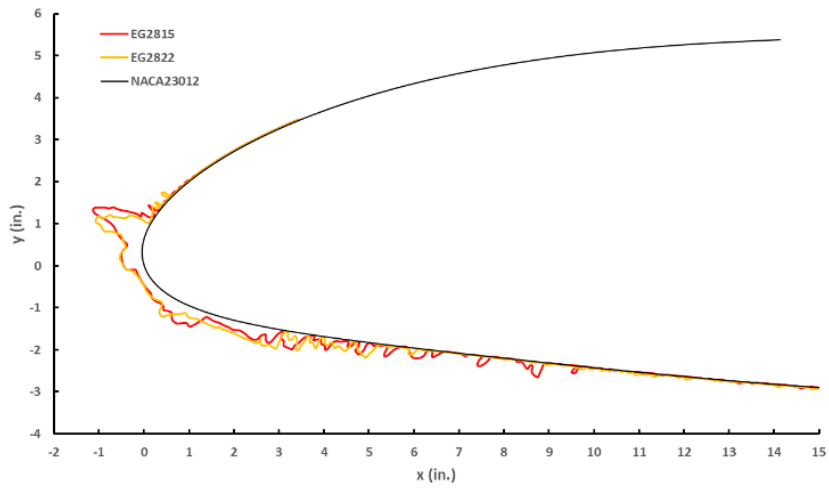

Figure 28. Ice shape profiles for repeat runs EG2815 and EG2822 from center line of 72-inch chord NACA 23012 airfoil model.

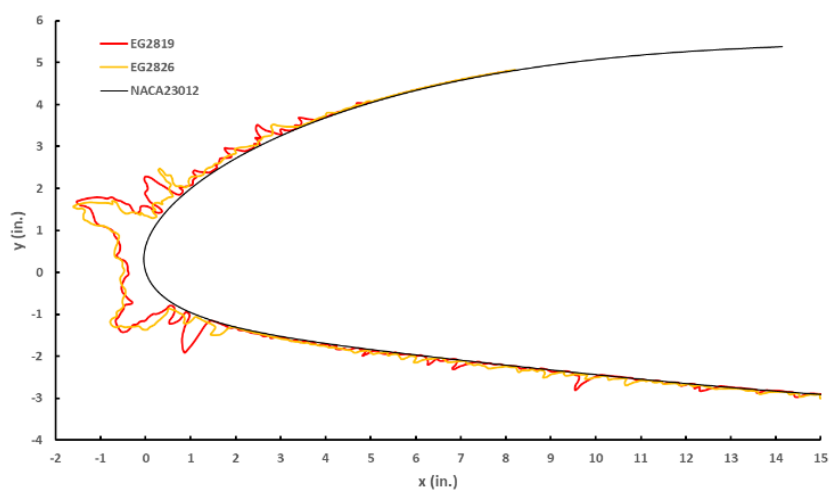

Figure 29. Ice shape profiles for repeat runs EG2819 and EG2826 from center line of 72-inch chord NACA 23012 airfoil model.

The same is true when examining the repeat runs for the monomodal cases of the same pairs. This is shown in Figure 28, depicting the ice shape tracings for EG2815 and EG2822.
Again, the main ice shapes are quite similar and the ice growth limits are approximately the same. There is definitely not the difference in ice roughness aft of the main shape as exhibited in Figures 20 and 22. The mass difference for these two runs is only $1 \%$ again compared to 23.4\% for EG2814/EG2815 and 25.6\% for EG2818/EG2822. The volume difference is $2.6 \%$ which is lower than the differences for the monomodal/bimodal pairs associated with these two runs.

The final repeat runs for the NACA 23012 airfoil model were EG2819 and EG2826. The centerline profiles for these two runs are shown in Figure 29. This figure indicates that the main ice shape and the ice roughness aft of the main shape are quite similar. This is also reflected in the mass difference which is $0.2 \%$ and the volume difference which is $1.7 \%$.

As in the NACA 0012 evaluation, the LEWICE code was used to examine the collection efficiency differences between 100 micron drops and 200 micron drops in order to further understand the differences between the monomodal/bimodal pairs and the repeat runs. This was performed for the various speed and angle of attack conditions. The results are shown in Figures 30 and 31 corresponding to the angle of attack conditions of 2 and 5 degrees, respectively.

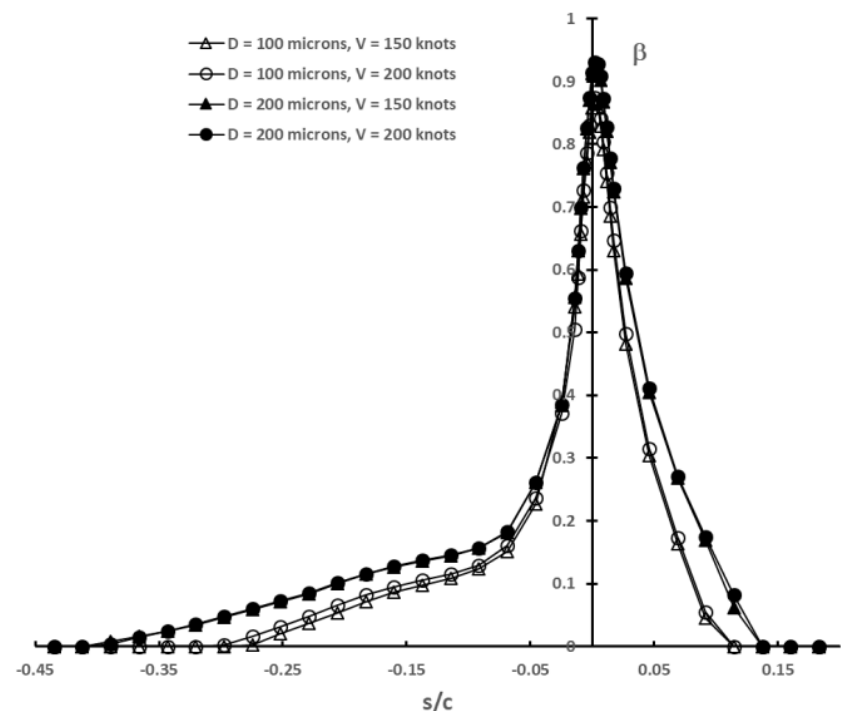

Figure 30. LEWICE collection efficiency results for the 72-inch NACA 23012 airfoil at $2^{\circ}$ angle of attack.

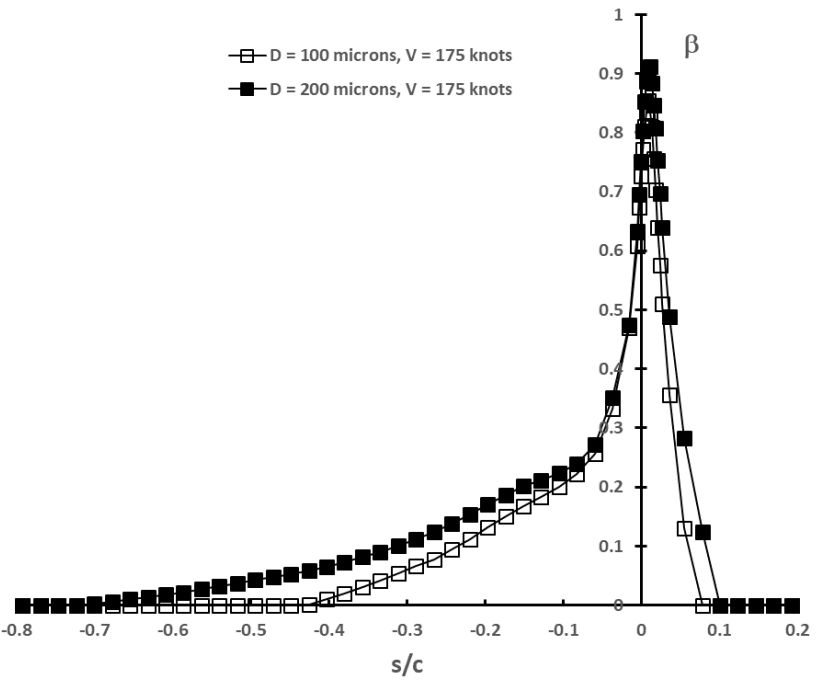

Figure 31. LEWICE collection efficiency results for the 72-inch NACA 23012 airfoil at $5^{\circ}$ angle of attack.

Page 8 
These LEWICE results indicate that the difference between 100 and 200 micron drop sizes result in a slightly higher collection efficiency and in impingement limits further aft. These results are as expected and suggest that there is somewhat more mass impinging for the bimodal conditions due to the amount of mass contained in drops with diameters between 100 microns and 200 microns as well as additional mass resulting from impingement further aft on the airfoil. The region near the leading edge shows only slight differences in collection efficiency which explains the very similar ice shapes which all form within the first 2 to 4 inches or $0.028 \mathrm{~s} / \mathrm{c}$ to $0.056 \mathrm{~s} / \mathrm{c}$.

\section{Discussion}

In previous studies [3, 4], the authors utilized scaling methods to select the conditions to be run for the monomodal and bimodal drop distributions by selecting a common reference condition and scaling the test conditions to match the reference. The advantage of that approach was that the scaling relationships allowed for the simulation of lower liquid water content conditions. The disadvantage of that approach is the dependence upon the scaling relationships introduces a possibility for ice shape difference that arises out of any uncertainty in the scaling relationships. Thus, the approach taken in this study was to eliminate the uncertainty due to scaling and accept that the conditions tested would be at large liquid water content conditions for both the monomodal and bimodal clouds.

The conditions selected for each monomodal/bimodal pair were exactly the same air velocity, air temperature, cloud liquid water content, cloud median volumetric diameter, and spray time. This resulted in the only difference between each pair of runs was the cloud drop size distribution. These distributions were as shown in Figure 2. The results of the study show that the main ice shapes for all the drop distribution pairs were as similar to each other as repeat runs of the same icing conditions. Thus, as expected for the same settings of the icing tunnel run, i.e. the parameters listed above, a very repeatable main ice shape was created regardless of the drop distribution. The results also showed that there was a greater amount of ice mass buildup for the bimodal distribution than for the monomodal distribution. Additionally, the volume of the ice in the sample area on the model was larger for the bimodal distribution than for the monomodal distribution.

This discrepancy between ice shape agreement and measureable differences in mass and volume appear to arise from several uncertainties inherent in ice shape comparisons at this time. The comparison of ice shape profiles is not an easily quantifiable measurement and is thus subject to interpretation. Wright [9] developed a software tool to measure and compare a small set of ice shape characteristics. These characteristics include elements such as horn height and horn angle. However these are not always easily recognizable on a given ice shape. For the ice shapes compared in this study it was not considered to be a useful tool for comparison. This lack of a highly accurate tool for ice shape profile measurements can thus lead to a mischaracterization of ice shape comparisons. In addition to the qualitative nature of ice shape profile comparison, ice shapes are highly complex three dimensional objects. The use of a two-dimensional ice shape profile to make comparisons inherently eliminates pertinent data from the evaluation. This is illustrated in the photographs in Figures 5, 7, 9, and 26. The scans shown in Figures 6, 8, and 10 indicate how these comparisons might be evaluated in a more quantitative manner.

The volume measurements performed for this study used the data from the scanner and the software employed for analysis of the scanned data [7] to determine the volume of the outer ice in the same measurement area from which the ice was extracted for the mass measurement. This volume was obtained by calculating the volume of the ice surface and subtracting the volume of the underlying airfoil which was also scanned for the purpose of determining this characteristic of the ice. It isn't clear how accurate the scanner measures the complex three dimensional ice shapes so there are still some uncertainties in that measurement. Further work on assessing the accuracy of that measurement for ice shapes is necessary. As a result, confidence in the volume measurement can be improved. Despite that, the volume measurement does provide some insight into ice shape differences that goes beyond the qualitative comparisons of ice shape profiles.

The comparison of ice geometry away from the main ice shape and towards the icing limits consists of evaluating small irregular threedimensional structures. Although difficult to measure, the mass contained in this region seems to be sufficient to contribute to some of the difference in ice mass measured for the monomodal/bimodal pairs of results. It is not clear, at this time, how to measure that contribution as it is highly subjective as to where the main ice shape ends and where the more disperse ice roughness region starts. The importance of the ice aft of the main shape is, of course, dependent upon the purpose of the testing. If the ice shape is being evaluated for its effects on aerodynamics the need to capture that in the tunnel may be different than if the coverage needed for an ice protection system is being evaluated.

The mass measurements have proven to be useful in that they are simple to perform, repeatable, and avoid the complexity of having to measure and evaluate the highly three dimensional ice shape geometry data. The mass measurements indicate that the bimodal drop distributions result in more mass accumulating on the airfoil than for the same icing condition with a monomodal drop distribution. While providing some insight into the differences between the icing distributions the mass measurements do not provide information as to why these differences arise. Further development of ice shape measurement methods and the analysis of that data is needed to gain greater insight into the differences in the ice shapes generated by these distributions.

The effective density was calculated for each ice shape by a simple ratio of measured ice mass to measured volume of the same region taken from the digital scans. These values were lower than the standard ice density of $0.95 \mathrm{~g} / \mathrm{cm}^{3}$. The ice shapes produced on the NACA 0012 airfoil had an average effective density of $0.753 \mathrm{~g} / \mathrm{cm}^{3}$ with the maximum variation between monomodal and bimodal density of $3.3 \%$. The ice shapes on the NACA 23012 airfoil had an average effective density of $0.809 \mathrm{~g} / \mathrm{cm}^{3}$ with the maximum variation between monomodal and bimodal density of $10 \%$. Surprisingly the greatest variation in effective density, of $24.4 \%$, was for the repeat cases EG2814 and EG2818. This seems to have been due to the large difference in measured volume between these two cases. Lastly, the very short sprays for EG2816 and EG2817 had the effective densities closest to the standard value for ice.

The similarity in main ice shape produced by the two cloud distributions suggests that an ice shape produced from a monomodal cloud may be sufficient to represent a freezing drizzle, MVD $<40$ micron condition if parameters connected to main ice shape are important. If on the other hand the icing limits or the mass of the ice shape are of importance then it may be necessary to match the specified distribution more closely. Given the differences between the two distributions tested in this study, it should be noted that both distributions differ from the freezing drizzle profile provided in the 
regulations. These results suggest that consideration of drop size variations should play an important role during an icing test campaign that has a focus on SLD conditions. Further studies are needed to confirm this for a wider variety of icing conditions and aircraft component shapes.

\section{Summary}

This study examined the influence of cloud drop distribution, in the freezing drizzle regime, on the resulting ice shape. The reason for this is that icing tunnels do not always recreate the drop distribution specified in Appendix O of CFR Chapter 14, Part 25 of Federal Regulations [10] regarding aviation. In the NASA Icing Research Tunnel, normal operations involving creation of a spray cloud with one of two sets of air-atomizing spray nozzles. This configuration creates drop distributions of the type shown as Cond1 and Cond 2 in Figure 2. These distributions are called monomodal in that when plotted as fraction of LWC as a function of drop size the resulting curve is typically bell-shaped in nature. Results from SLD flights plotted in the same way can have distributions with two distinct peaks and are called bimodal distributions.

Results from this study have indicated the following trends.

- Ice shapes from bimodal distributions and from monomodal distributions having the same icing conditions (i.e. air velocity, air temperature, LWC, MVD) result in very similar main ice shapes.

- Mass and volume measurements indicate that the bimodal ice shapes have more mass and volume than their monomodal pairs.

- It appears from examination of photographs and from subsequent analysis with LEWICE that the additional mass may be contained in the region aft of the main ice shape where large scale ice roughness is found.

- The bimodal condition also appears to have somewhat larger icing impingement limits which also may contribute to the discrepancies in mass and volume.

- Current methods for measuring ice shape in these areas aft of the main ice shape are not well developed nor are methods for establishing icing limits along the span of the airfoil or wing.

\section{Recommendation}

Further testing using this approach should be undertaken to confirm that the differences in ice mass and volume between ice shapes produced with bimodal and monomodal drop distributions continue the same trends over a wider range of icing conditions and model geometries. This should include swept airfoil geometries as well as other surfaces that typically have ice protection systems since mass and icing limit are important in the design of such systems.

Additionally, better methods for documenting the mass, shape, and extent of ice aft of the main ice shape should be developed. Specifically, it is recommended that future tests of this nature should document icing limits directly for characterization of differences in ice accretion results between monomodal and bimodal drop distributions. This would enable the determination of whether the enhanced impingement in such regions is the main contributor to the differences in mass and volume measurements for the types of comparisons performed in this study.

\section{References}

1. Cober, S. G., G. A. Isaac, and J. Walter Strapp, "Characterization of Aircraft Icing Environments that Include Supercooled Large Drops." J. Appl. Meteor. 40:1984-2002, 2001, https://doi.org/10.1175/15200450(2001)040<1984:COAIET > 2.0.CO;2.

2. King-Steen, Laura, E. and Ide, Robert, F., "Creating a Bimodal Drop-Size Distribution in the NASA Glenn Icing Research Tunnel," 9th AIAA Atmospheric and Space Environments Conference, AIAA AVIATION Forum, Denver, CO, June 5-8, 2017, AIAA Paper 2017 4477.

3. Potapczuk, M.G., Tsao, J. and King-Steen, L.E., "Bimodal SLD Ice Accretion on a NACA 0012 Airfoil Model”, 9th AIAA Atmospheric and Space Environments Conference, AIAA AVIATION Forum, Denver, CO, June 5-8, 2017, AIAA Paper 2017-4478. https://doi.org/10.2514/6.2017-4478

4. Potapczuk, M.G. and Tsao, "Further Examinations of Bimodal SLD Ice Accretion in the NASA Icing Research Tunnel", 2018 Atmospheric and Space Environments Conference, AIAA AVIATION Forum, Atlanta, GA, June 25-29, 2018, AIAA Paper 2018-3182. https://doi.org/10.2514/6.2018-3182

5. Steen, L.E., Ide, R.F., Van Zante, J.F., and Acosta, W. J., "NASA Glenn Icing Research Tunnel: 2014 and 2015 Cloud Calibration Procedure and Results," NASA/TM2015-218758, May 2015.

6. Lee, S., Broeren, A.P., Kreeger, R.E., Potapczuk, M.G., and Utt, L., "Implementation and Validation of 3-D Ice Accretion Measurement Methodology," AIAA 6th Atmospheric and Space Environments Conference, Atlanta, GA, June 16-20, 2014, AIAA Paper 2014-2613. https://doi.org/10.2514/6.2014-2613

7. Geomagic Wrap, http://www.geomagic.com/en/products/wrap/overview, 3D Systems Corp., April 27, 2017.

8. Wright, W. B., "User's Manual for LEWICE 3.2", NACA CR-2008-214255, Nov. 2008.

9. Wright, W. B., "Validation Methods and Results for a Two-Dimensional Ice Accretion Code,: J. of Aircraft, Vol. 35, No, 5, Sept. 1999.

10. CFR 14, Part 25, Appendix O, "Supercooled Large Drop Icing Conditions," http://www.ecfr.gov.

\section{Contact Information}

Mark Potapczuk, Ph.D., Work phone: (216) 433-3919, e-mail: mark.g.potapczuk@nasa.gov

Jen-Ching Tsao, Ph. D., Work phone: (216) 433-2411, e-mail: jenching.tsao-1@nasa.gov

\section{Acknowledgments}

The authors would like to thank Laura King-Steen, Judith Van Zante, Emily Timko, and Robert Ide for their expert input on the bimodal cloud conditions and how they are produced in the NASA Icing Research Tunnel. The authors would also like to thank the staff of the IRT for their assistance during preparation for testing and during test 
operations. This work is supported by the Aerosciences Evaluation and Test Capabilities Project.

\section{Definitions, Acronyms, Abbreviations}

bimodal distribution A bimodal distribution refers to the drop size distribution of an icing cloud that has two local maxima in a plot of normalized mass distribution $[\Delta(\mathrm{LWC}) / \Delta \log ($ diameter $)]$, as a function of drop size

LEWICE An ice accretion simulation code developed by

NASA.

monomodal distribution A monomodal distribution refers to the drop size distribution of an icing cloud that has a single local maxima in a plot of normalized mass distribution

$[\Delta(\mathrm{LWC}) / \Delta \log ($ diameter $)]$, as a function of drop size

FAA Federal Aviation Administration

IRT Icing Research Tunnel

LWC Liquid Water Content

MVD Median Volumetric Diameter

NACA National Advisory Committee on Aeronautics

NASA National Aeronautics and Space Administration

SLD Supercooled Large Drop 
Page 12 